Analysis of In situ Observations of Cloud Microphysics from M-PACE Final Report, DOE Grant Agreement No. DE-FG02-06ER64168

\author{
Michael R. Poellot \\ Department of Atmospheric Sciences \\ University of North Dakota \\ Grand Forks, North Dakota
}

January 9, 2009 


\section{Analysis of In situ Observations of Cloud Microphysics from M-PACE Final Report, DOE Grant Agreement No. DE-FG02-06ER64168}

\section{Objectives}

The importance of Arctic cloud properties to the surface and atmosphere radiative flux budget is well known and accurate representation of these clouds is essential to proper modeling of the Arctic environment. One of the interesting characteristics of Arctic clouds is the prevalence of mixed phase cloud layers that persist for hours or even days. To help better understand these clouds, the Department of Energy sponsored the Mixed-Phase Arctic Cloud Experiment (M-PACE) during fall 2004. The University of North Dakota (UND) Cessna Citation research aircraft platform was operated for MPACE to obtain in situ measurements of cloud microphysical properties. The proposed research is centered on analysis of the Citation measurements.

The objectives of the proposed research are threefold:

1. to characterize certain microphysical properties of clouds sampled during MPACE, including spatial variability, precipitation formation, ice multiplication;

2. to examine instrument performance and certain data processing algorithms; and

3. to collaborate with other M-PACE investigators on case study analyses.

\section{Microphysical Characterization}

\section{Analyses of Spatial Distribution}

(from Brown, 2007 thesis)

The cloud water and ice content has been analyzed with respect to large scale distribution of liquid water, ice/liquid water partitioning in cloud, and small- to mid-scale variability of cloud properties. The analysis efforts to date have focused on stratus clouds containing significant liquid water amounts. Such conditions were encountered under two different synoptic regimes and included missions flown on September 30 and October 1 (regime 1) and October 6, 8, 9 and 10 (regime 2). Regime 1 was characterized as unsettled with a series of weak lows and an upper trof affecting conditions. Regime 2 found the area under a ridge with a surface high to the northeast over the pack ice. During this second regime, a small mid-level system passed through on October 6.

In situ data collected by the UND Citation were used, with a nominal resolution of $1 \mathrm{~Hz}$ or about 80 meters. The flight profiles employed were primarily spiral climbs and descents over ground sites at Oliktok Point and Barrow and ramp climbs and descents flown between those two sites (a distance of approximately $250 \mathrm{~km}$ ). This sampling mode has provided a challenge to deriving the horizontal distribution of cloud parameters. The time series of samples in the ramps represents variations in both the horizontal and vertical dimension. For example, cloud water and droplet size generally increased with height in the study clouds. There were periods when the aircraft was flown at a constant altitude but these periods were generally brief and/or out of cloud. Time series of data 
from level in-cloud legs have been examined to characterized distributions on smaller scales; other techniques have been used to derive larger scale cloud properties.

Two consecutive missions were flown on October 9 and 10 UTC (October 9 local time) that sampled the same single cloud event. The cloud was forced by cold air flowing off Arctic ice pack over open ocean water and cloud rolls developed in rolls parallel to the flow. The overall depth of the cloud increased with distance from the ice pack. To analyze these data the cloud samples were partitioned according to the vertical location in cloud, i.e., lower third, middle third or upper third of the cloud layer. This yielded a total of eight values in the lower two thirds of the cloud on the first flight, with six points in the top third due to incomplete sampling, and five average sample points at each level on the second flight. On average, liquid water content and mean droplet diameter increased from $0.10 \mathrm{~g} \mathrm{~m}-3$ and 12 microns in the lower third to $0.32 \mathrm{~g} \mathrm{~m}-3$ and 20 microns in the upper third of the layer, with droplet size about 2.5 microns larger on the second flight. Droplet concentrations were constant throughout the layer on each flight but were significantly lower on the second $(55 \mathrm{~cm}-3)$ relative the first $(75 \mathrm{~cm}-3)$.

\section{Large-scale Variability}

This analysis yields several interesting results. One is that the variability in LWC and mean diameter with distance in both flights suggests microphysical variations on a scale of 150-175 km and the larger number of samples on the first mission also reveals variability on a scale about $1 / 3-1 / 2$ of this value. A second feature is that the microphysical properties of the cloud changed noticeably over the 4 hours that encompassed both sample periods. Finally, the constant value of droplet concentration in the vertical indicates that this parameter could be used as a measure of horizontal variability in time series of ramp leg data.

Another approach in determining the horizontal distribution of liquid water was to examine the variability of liquid water path (LWP) through the layer. The LWP was computed for each ramp climb and descent that extended through the full cloud layer. This was done for the October 9 and 10 missions and also for the single layer flights on September 30 and October 1, although the profiles for the two additional flights occurred relatively close to Oliktok Point. The LWP values ranged from $<50 \mathrm{~g} \mathrm{~m}^{-2}$ to over $200 \mathrm{~g}$ $\mathrm{m}^{-2}$, with the highest values occurring on September 30. The LWP maxima on October 9 were spaced approximately $200 \mathrm{~km}$ apart; the distribution was more uniform on the $10^{\text {th }}$ (but there were fewer points). Late in the flight on the $10^{\text {th }}$ seven consecutive spirals through the layer were conducted over Barrow. Over a 45-minute period, the LWP increased by $60 \%$, which at a mean layer advection speed of $12 \mathrm{~m} \mathrm{~s}^{-1}$ corresponds to a cloud layer spatial distance of about $30 \mathrm{~km}$.

\section{$\underline{\text { Small- to Mid-scale Variability }}$}

Analysis of the ice and liquid water data plus examination of high resolution images of cloud particles indicated that regions of all ice and all liquid were separated at times by only tens of meters. Times series of data from level legs were also analyzed to 
look for characteristic scales of variability. Parameters considered included liquid water content, droplet concentration and size, and vertical wind speed. The longest in-cloud level flight segment was 275 seconds, or about $22 \mathrm{~km}$ in length. There did appear to be a scale length of approximately 100 second $(8 \mathrm{~km})$ in these fields. This may have been a reflection of the convective roll features in the cloud layer.

\section{Horizontal Scale Analysis by Autocovariance Function}

Another method was employed for examining horizontal variability on a continuous spectrum of scales, from less than $5 \mathrm{~km}$ to greater than $100 \mathrm{~km}$. A Fourier analysis of the discrete in-situ time series data was performed to determine scales of variability continuously from about 160 meters up to roughly $250 \mathrm{~km}$. A few challenges were faced when performing this analysis. First, the level leg samples were not long enough to resolve large scales. The length of the level leg samples was restricted due to aircraft icing issues. Therefore, the series of ramped ascents and descents had to be used. However, this introduced problems because these sampling modes scaled the entire depth of the cloud, thereby adding vertical variations in cloud properties. Also, during the ramped ascents and descents the aircraft often exited the cloud layer. Due to the resulting gaps in microphysical data a Fourier transform could not be directly applied to the data.

In order to perform the analysis a few assumptions had to be made. The first was to assume a constant true airspeed of $80 \mathrm{~m} \mathrm{~s}^{-1}$. The data could then be converted from the time domain to distance domain, while keeping the data regularly distributed. Also, the data from each ramped profile could be related to each other in the distance domain, whereas, in the time domain the lengths of the gaps of data were arbitrary. The next assumption was the vertical displacement of the aircraft was negligible relative to the horizontal displacement. Measurements show the vertical displacement was typically two orders of magnitude less than the horizontal. This means the slantwise distance covered during the sampling could be approximated as horizontal distance. Therefore, it could be assumed that all variations in cloud properties sampled were in the horizontal direction.

Due to the gaps in the data the power spectrum had to be derived from the autocovariance function (ACVF). The ACVF was calculated from the time series by only using lagged pairs that contained two "in-cloud" values. The total number of samples at each lag is obviously much less than from a time series with no gaps. However, there were still a statistically significant number of samples at each lag. Once the ACVF of the time series was calculated it was possible to obtain the power spectrum, because the ACVF and power spectrum form a Fourier transform pair.

The data that were used come from the flight on October 9. A series of eight ramped ascents and descents were performed from Oliktok Point to Barrow. The aircraft collected 2447 seconds of data, which at a constant true airspeed of $80 \mathrm{~m} \mathrm{~s}^{-1}$ translates to about $195 \mathrm{~km}$. The cloud microphysical property that was used was droplet total number concentration measured from the Forward Scattering Spectrometer Probe (FSSP), because measurements show that this property does not show significant variation as a 
function of height above cloud base in this case. Measurements also show that variability in number concentration is co-located with other cloud properties, such as mean droplet diameter and liquid water content. Therefore, it can be assumed that scales of variability of these properties will be similar. This analysis (Fig. 1) revealed two distinct peaks in harmonic variance at $5.4 \mathrm{~km}$ and $12.3 \mathrm{~km}$, along with several smaller peaks at scales from $5 \mathrm{~km}$ down to $1 \mathrm{~km}$. There was also a peak apparent at approximately $67 \mathrm{~km}$; however, the spectral resolution at this wavelength is poor. The peak at $12.3 \mathrm{~km}$ could be due to the convective rolls in the boundary layer cloud, and it is unclear at the present what is responsible for the peak at smaller scales.

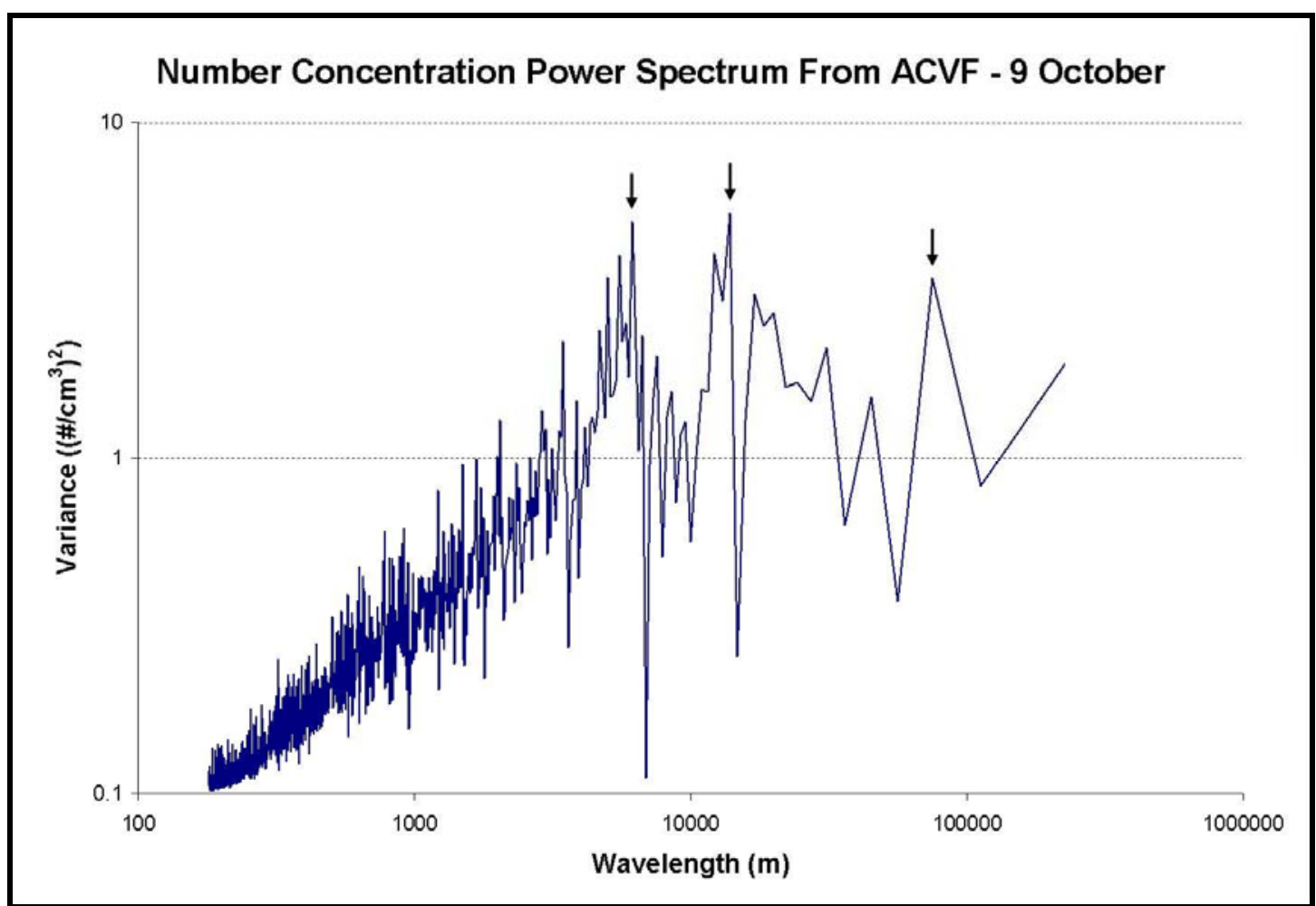

Figure 1: Power spectrum of FSSP number concentration derived from ACVF. Arrows indicate three largest peaks in harmonic variance.

The main drawback of this analysis is the large uncertainty in the amount of harmonic variance at each scale. Comparing the results of this method versus a direct Fourier transform on a time series of data with no gaps shows this method dampens the peaks in harmonic variance significantly at large wavelengths and the variance is too high at lower wavelengths. This method shows excellent agreement in the location of the peaks, however. Therefore, the scales of variability found in this analysis are accurate, while the amount of variance is at any wavelength contains significant uncertainty. Further analysis will need to be performed to get an estimate of the uncertainty and obtain a better estimate of harmonic variance. 


\section{Ice/Water Partitioning}

Liquid and ice water path values and liquid water fraction were calculated for profiles on the flights listed in Table 1. The liquid water fraction (LWF) is computed as

\section{$\mathrm{LWF}=\mathrm{LWP} /(\mathrm{LWP}+\mathrm{IWP})$}

There are clear differences in the IWP and LWP values and relative fraction between the single and multi-layer periods. Values of LWP for multi-layer cases are less than one-third as large as for single layer clouds, while IPW values for multi-layer clouds are more than three times as large as for single layer. This is reflected in the values of the liquid water fraction. This is also graphically represented by summary probability distribution function diagrams for single and multi-layer cases in Figures 2 and 3.

Table 1. Ice water path (IWP), liquid water path (LWP) and liquid water fraction (LW) fraction means and standard deviation.

\begin{tabular}{|c|c|c|c|}
\hline Date & IWP $\left(\mathbf{g ~ m}^{-2}\right)$ & LWP $\left(\mathbf{g ~ m}^{-2}\right)$ & LW Fraction \\
\hline & Mean, $\boldsymbol{\sigma}$ & Mean, $\boldsymbol{\sigma}$ & Mean, $\boldsymbol{\sigma}$ \\
\hline & & & \\
\hline $\mathbf{1 0 / 5}$ & $41.9 \pm 23.1$ & $17.95 \pm 16.6$ & $0.26 \pm 0.18$ \\
\hline & & & \\
\hline $\mathbf{1 0 / 6}$ & $58.2 \pm 53.0$ & $39.9 \pm 22.4$ & $0.44 \pm 0.19$ \\
\hline & & & \\
\hline $\mathbf{1 0 / 8}$ & $21.5 \pm 30.5$ & $46.1 \pm 32.3$ & $0.79 \pm 0.17$ \\
\hline & & & \\
\hline $\mathbf{1 0 / 9}$ & $10.1 \pm 8.6$ & $126.4 \pm 42.3$ & $0.93 \pm 0.06$ \\
\hline & & & \\
\hline $\mathbf{1 0 / 1 0}$ & $11.9 \pm 21.4$ & $118.4 \pm 23.5$ & $0.93 \pm 0.08$ \\
\hline & & & \\
\hline overall & $25.5 \pm 31.1$ & $77.7 \pm 54.5$ & $0.69 \pm 0.32$ \\
\hline
\end{tabular}
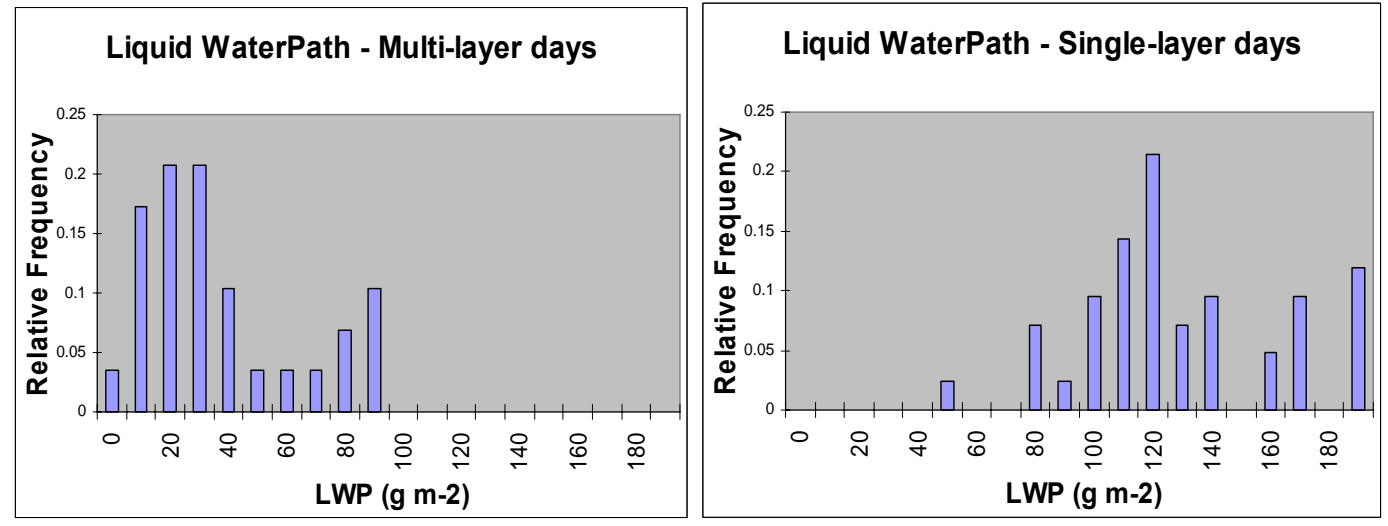

Figure 2. Liquid water path frequency distribution for multi-layer and single-layer days 

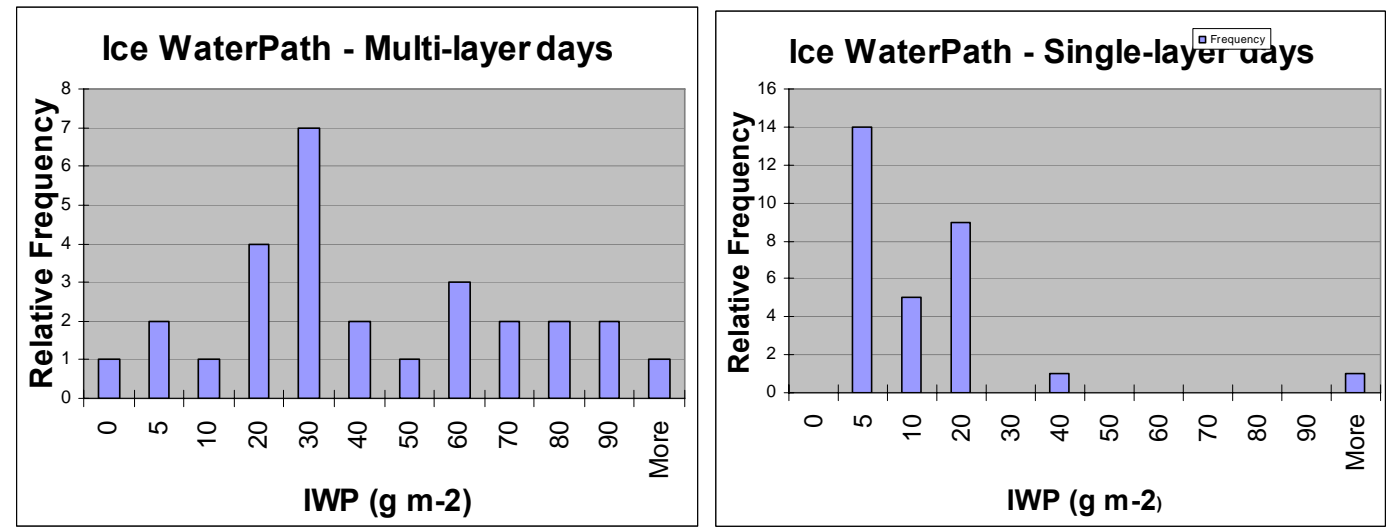

Figure 3. Ice water path frequency distribution for multi-layer and single-layer days

\section{Phase Clustering}

One additional estimate of variability may be derived through an examination of the clustering of cloud particle phase. This was done to determine how the arctic stratus cloud ice is distributed in the horizontal dimension, which is needed for proper parameterization of sub-grid scale ice/water partitioning. If the ice is assumed to be distributed uniformly through a grid box, the calculated cloud albedo may be biased relative to a distribution where the ice occurs in clusters or pockets. This would be due to the difference in albedo between all ice and all water clouds (McFarquhar and Cober, 2004).

The clustering of particle phase was derived for flight segments when the Citation was flying straight legs, but not necessarily at a constant altitude. Cluster values denote the number of contiguous samples of like phase. These were derived from 10-second average data and so a cluster value of 10 , for example, corresponds to 100 seconds. At an airspeed of approximately $90 \mathrm{~m} \mathrm{~s}^{-1}$ this would represent a horizontal distance of $9 \mathrm{~km}$.

Cluster sizes for multi- and single-layer days are presented in figures 4 and 5 . These figures show that cluster sizes were approximately twice as large on single-layer days (average size of 11.8 samples (118 seconds)) as on multi-layer days (average size of 5.7 samples ( 57 seconds)). This implies that the single layer clouds are more uniform in horizontal extent of phase.

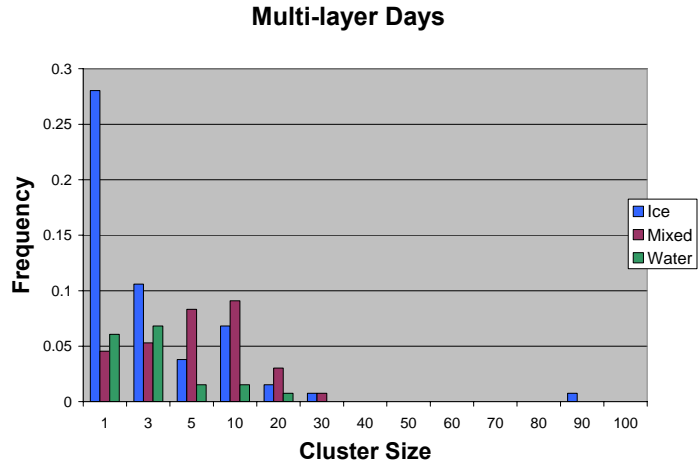

Figure 4. Cluster size on multi-layer days

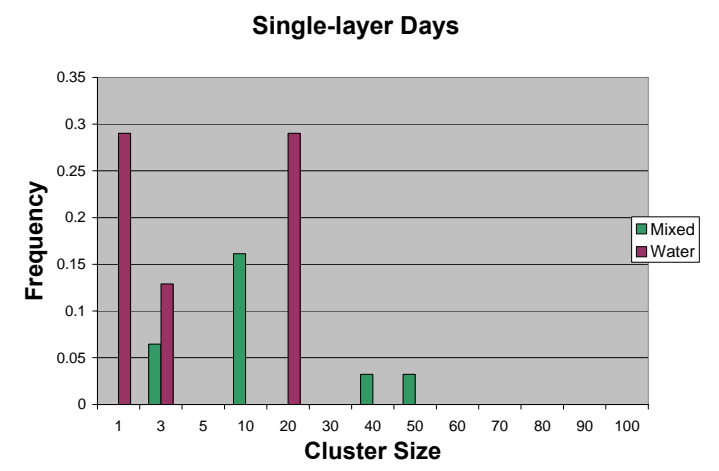

Figure 5. Cluster size on single-layer days 
An important consideration to the interpretation of these figures is that much of the cluster values are derived from flight segments when the aircraft was climbing or descending. Since most of the cloud layers sampled contained a liquid water layer near cloud top, the clusters of liquid water represent times when the aircraft was transiting the liquid layer and therefore are artificially low in horizontal extent. Therefore, the cluster size of liquid patches is most likely underestimated.

\section{Precipitation formation mechanisms}

Precipitation formation mechanisms were examined as part of a study of MPACE data by McFarquhar et al. (2007). To determine the phase of particles with D $>53$ $\mu \mathrm{m}$, a habit identification scheme was applied to the CPI images taken in mixed phase conditions. Of the 28530 -s mixed-phase time periods, only $18 \%$ had at least a single particle between $0.053<\mathrm{D}<0.125 \mathrm{~mm}$ that was clearly spherical and drizzle; only $19 \%$ had a particle between $0.053<\mathrm{D}<0.512 \mathrm{~mm}$ that was drizzle. There were typically nonspherical particles between $0.053<\mathrm{D}<0.125 \mathrm{~mm}$, suggesting many particles in this size range were ice. This indicates that although a coalescence process was active in forming precipitation, the dominant mechanism was through ice phase growth.

\section{Ice Formation}

While Prenni et al. (2007) found that ice crystal concentrations measured in MPACE correlated well with IN concentrations, there were many occasions when IN concentrations underestimated crystal numbers. This remains a subject of discussion due to uncertainties in the measurement of both IN and small ice crystals. Several mechanisms were explored in the current study to help resolve this discrepancy.

As an indirect measure of IN activity, liquid water fraction is plotted as function of cloud top temperature in figure 6. Again, liquid water fraction is derived from the liquid and ice water paths measured during ramps and spirals. As expected from classical nucleation theory, there is a greater relative presence of ice when cloud tops are located at colder temperatures.

As noted above, that there was more ice present on days with multi-layer clouds. It is possible that this was due to natural seeding of lower cloud layers by ice nucleated in the higher cloud. This was likely an active mechanism on multi-layer days as ice crystals were observed between cloud layers. It is also possible that the larger falling crystals experienced some fracturing, which could lead to ice multiplication. However, the uncertainties introduced by the shattering of crystals on the airborne probes prevents us from determining if this was taking place. 


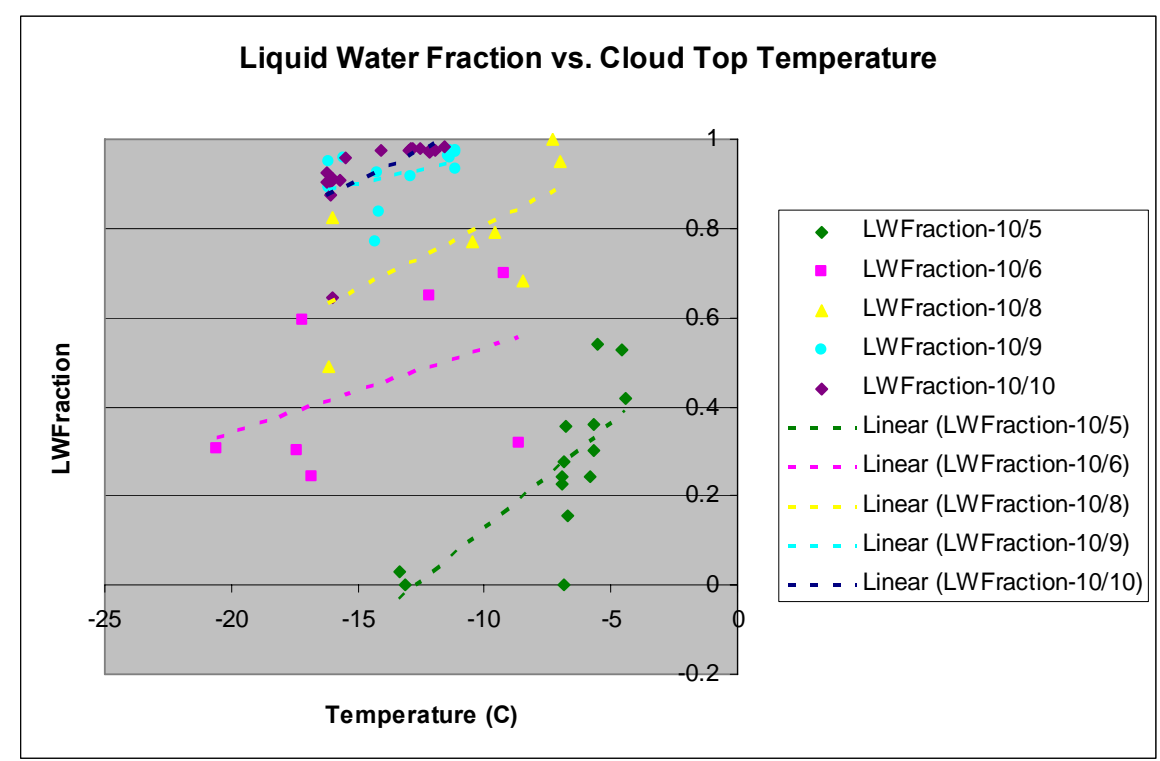

Figure 6. Liquid water fraction as a function of cloud top temperature. Dotted lines are linear best fit correlations.

A trajectory analysis was performed using NOAA's HYSPLIT model to find relations between cloud microphysical properties and the cloudy air masses' source region and trajectory characteristics (Brown, 2007). Back trajectories originating over Barrow, Alaska on Oct. 1, 6, 8, and 10 were calculated at three levels: sub-cloud, in cloud, and above cloud. The model was run backwards in time for a 72 hour period for all flights, with the exception of Oct. 1, which was run backwards 60 hours. GFS analysis data at six hour intervals was used as input for the model. The initial time of each model run was chosen to be the GFS model output time closest to the flight time from which the cloud properties were taken.

Results of the trajectory analysis for the in-cloud layers show four distinct characteristics in the trajectories. The air parcels experienced either large scale vertical ascent for a significant duration of time or no vertical motion, and originated over land or water. The cases on Oct. 1 and 10, which contain very little ice phase clouds, all show the parcels experienced very little or no vertical ascent and had horizontal trajectories over the ocean. The cases on Oct. 6 and 8, which contained significantly more ice phase clouds, both show that parcels experienced a significant amount of large scale ascent and trajectories passed over land. This limited data set suggests a possible influence of air mass source on IN concentration or activity, or that large scale ascent produces higher/colder clouds which then nucleate higher ice crystal concentrations. This latter mechanism would reinforce the natural seeding hypothesis.

\section{Summary of Microphysical Characteristics}

- There is evidence of larger scale variability in scales of 50 to $>150 \mathrm{~km}$.

- Smaller scale variability ranged from tens of meters (mixed ice/water) to $\sim 12 \mathrm{~km}$ (liquid water, dynamics).

- LWP varied from $<10 \mathrm{~g} \mathrm{~m}-2$ in multilayer clouds to $>200 \mathrm{~g} \mathrm{~m}-2$ in single layer clouds. 
- Sampled clouds had a substantial (25-45\%) mixed phase water content.

- Single layer clouds were more uniform in the horizontal extent of cloud phase than multi-layer clouds.

- Although the water/ice partitioning at a given point in cloud was not well-correlated with temperature (in the range of -5 to $-15^{\circ} \mathrm{C}$ ), the liquid fraction did vary directly with cloud top temperature.

- Cloud layers experiencing significant large scale ascent contained more ice than those that did not ascend.

- The ice phase mechanism dominates precipitation formation.

\section{Instrument Performance}

\section{CN counter}

One of the instruments carried on the Citation for MPACE was a TSI 3270 condensation nuclei $(\mathrm{CN})$ counter. Initial inspection of the data during the field campaign showed apparent normal operation of the instrument. However, detailed post-field analysis revealed intermittent undercounting. An effort was made to see if a portion of the data could be recovered. Unfortunately, there is no clue as to when the instrument was working properly. Thus, these data have been flagged as unreliable and should not be used in analysis.

\section{Hygrometer}

Water vapor concentrations were measured by a Maycomm Tunable Laser Diode (TDL) hygrometer. These data appear to be contaminated and it was determined that the instrument had an internal leak. This leak apparently was created during a vendor calibration immediately prior to the campaign. Ambient and cabin pressures were referenced during periods when the aircraft was in liquid water cloud to determine whether there were any periods of data that might be good. The leak allowed cabin air to be mixed with the outside sample air, meaning that values are only good for relative comparisons.

\section{Bulk Water Measurements}

The performance of liquid water probes used in MPACE was assessed by McFarquhar et al. (2005). Measurements of bulk liquid water were compared for times when no significant amounts of ice were present. Figure 7 shows that good agreement between LWCs estimated from FSSP and 1DC size distributions against the bulk LWCs measured by the King and CSI probes for liquid conditions is obtained, suggesting measurements from different probes are consistent for liquid conditions. FSSP data cannot typically be used quantitatively for glaciated conditions (e.g., Gardiner and Hallett (1985). 


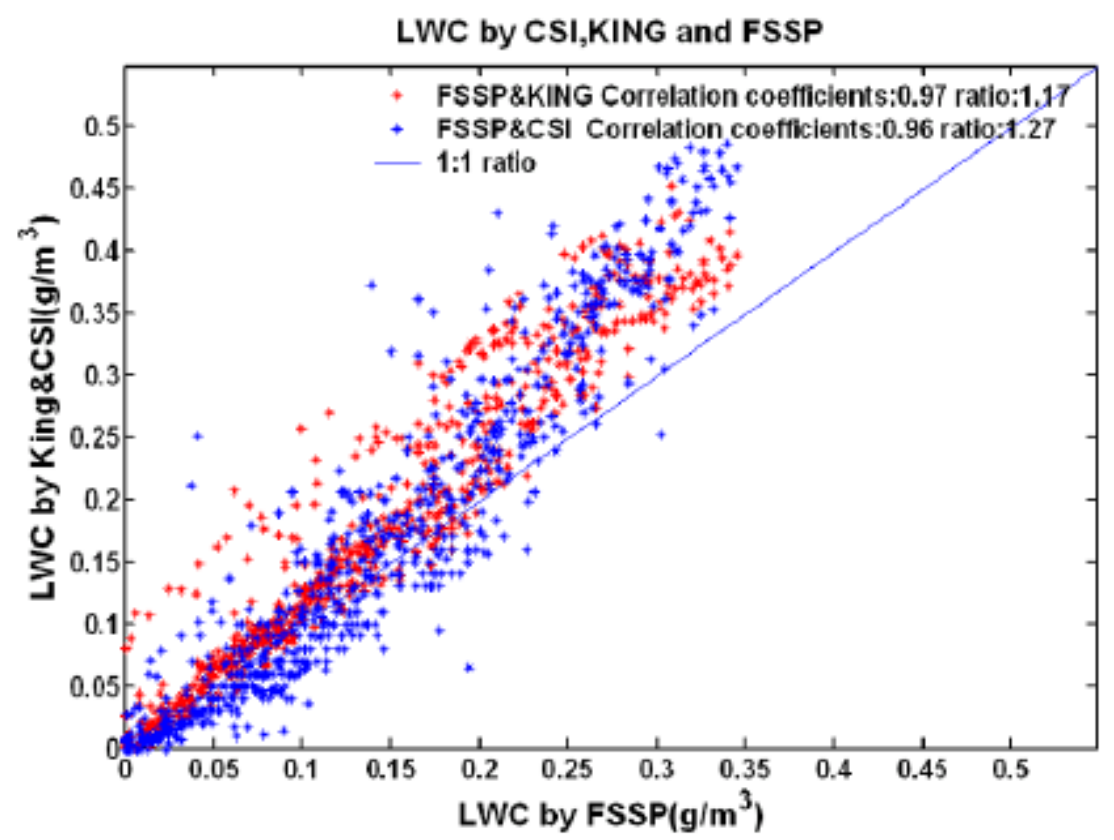

Figure 7. Bulk LWC from King/CSI vs. LWC derived from FSSP PSD. For $L W C<0.2 \mathrm{~g} \mathrm{~m}$-3, King and CSI measurements differ from FSSP by 9\% and 21\% respectively; for LWC >0.2 g m3 , King and CSI measurements differ from FSSP by $25 \%$ and $29 \%$ respectively. Data are shown

\section{Collaborative Work}

Refereed Publications:

Shupe, M.D., P. Kollias, M. Poellot, and E. Eloranta, 2008: On Deriving Vertical Air Motions from Cloud Radar Doppler Spectra. J. Atmos. Oceanic Technol., 25, 547-557.

Fridlind, A.M., A.S. Ackerman, G. McFarquhar, G. Zhang, M.R. Poellot, P.J. DeMott, A.J. Prenni, and A.J. Heymsfield, 2007: Ice properties of single-layer stratocumulus during the Mixed-Phase Arctic Cloud Experiment (M-PACE): Part II, Model results. J. Geophys. Res., 112, D24202, doi:10.1029/2007JD008646.

McFarquhar, G. M., G. Zhang, M. R. Poellot, G. L. Kok, R. McCoy, T. Tooman, A. Fridlind, and A. J. Heymsfield (2007): Ice properties of single-layer stratocumulus during the Mixed-Phase Arctic Cloud Experiment: 1. Observations, J. Geophys. Res., 112, D24201, doi:10.1029/2007JD008633.

Prenni, A. J., P. J. DeMott, C. Twohy, M. R Poellot, S. M. Kreidenweis, D. C. Rogers, S. D. Brooks, M. S. Richardson, and A. J. Heymsfield (2007), Examinations of ice formation processes in Florida cumuli using ice nuclei measurements of anvil ice crystal particle residues, J. Geophys. Res., 112, D10221, doi:10.1029/2006JD007549.

Verlinde, et al., 2007: The Mixed-Phase Arctic Cloud Experiment. Bull. Amer. Meteor. Soc., 88, 205-221. 
Prenni, A., P.DeMott, D. Rogers, S. Kreidenweis, G. McFarquhar, G. Zhang and M. Poellot, 2008: Ice nuclei characteristics from M-PACE and their relation to ice formation in clouds. Tellus B. - accepted for publication

Klein, et al., 2008: Intercomparison of model simulations of mixed-phase clouds observed during the ARM Mixed-Phase Arctic Cloud Experiment. Part I: Single-layer cloud. Submitted to QJRMS.

Morrison, et al., 2008: Intercomparison of model simulations of mixed-phase clouds observed during the ARM Mixed-Phase Arctic Cloud Experiment, Part II: Multilayered cloud. Submitted to QJRMS.

\section{Conference Proceedings:}

Poellot, M., D. Brown, G. McFarquhar and G. Zhang, 2008: Distribution of Ice and Water in Arctic Stratus Clouds During MPACE. Proceedings, $18^{\text {th }}$ Atmospheric Radiation Measurement (ARM) Science Team Meeting, Norfolk.

Zhang, G., G. McFarquhar, J. Verlinde, M. Poellot, G. Kok, and A. Heymsfield, 2007: Comparing and Explaining Differences in Microphysical Properties of Singlelayer and Multi-layer Boundary Clouds Observed During MPACE. $17^{\text {th }}$ Atmospheric Radiation Measurement (ARM) Science Team Meeting, Monterey.

Ghan, S., et al., 2007: Indirect Semi-Direct Aerosol Campaign. 17 ${ }^{\text {th }}$ Atmospheric Radiation Measurement (ARM) Science Team Meeting, Monterey.

Brown, D., and M. Poellot, 2007: Variability of Arctic Cloud Properties from in-Situ Measurements. $17^{\text {th }}$ Atmospheric Radiation Measurement (ARM) Science Team Meeting, Monterey.

Shupe,M, P. Kollias, G. McFarquhar, M. Poellot and E. Eloranta, 2007: Vertical Motions in Arctic Mixed-Phase Stratus. $17^{\text {th }}$ Atmospheric Radiation Measurement (ARM) Science Team Meeting, Monterey.

Zhang, G., G. McFarquhar, M. Poellot, J. Verlinde, G. Kok, A. Heymsfield, 2006: Contrasting properties of single-layer and multi-layer Arctic stratus sampled during the Mixed Phase Cloud Experiment (MPACE), Eos Trans. AGU, 87(52), Fall Meet. Suppl., Abstract A33B-0987.

Poellot, M., D.Brown, G. McFarquhar, G. Zhang, A. Heymsfield, 2006: A Case Study of Horizontal Variability in Arctic Cloud Microphysical Properties. AMS 12th Conference on Cloud Physics, Madison.

McFarquhar, G., G. Zhang, M. Poellot, G. Kok, A. J. Heymsfield, and J. Verlinde, 2006: In-situ observations of vertical profiles of mixed-phase clouds during the Mixed Phase Arctic Cloud Experiment (MPACE): implications for climate studies. AMS 12th Conference on Cloud Physics, Madison. 
Zhang. G., G.M. McFarquhar, J. Verlinde, M. Poellot, and A. Heymsfield, 2006: Contrasting Properties of Single-Layer and Multi-Layer Arctic Stratus Sampled During the Mixed-Phase Cloud Experiment. Proceedings of the Sixteenth Atmospheric Radiation Measurement (ARM) Science Team Meeting, Albuquerque.

Spangenberg, D., P. Minnis, S. Sun-Mack, M.D. Shupe, M.R. Poellot, 2006:

Characterization of Mixed-Phase Clouds During Mixed-Phase Arctic Cloud Experiment from Satellite, Ground-Based, and In-Situ Data. Proceedings of the Sixteenth Atmospheric Radiation Measurement (ARM) Science Team Meeting, Albuquerque.

Poellot, M., and D. Brown, 2006: A Case Study of Horizontal Variability in Arctic Cloud Microphysical Properties. Proceedings of the Sixteenth Atmospheric Radiation Measurement (ARM) Science Team Meeting, Albuquerque.

Spangenberg, D, M. Shupe, M. R. Poellot, and P. Minnis, 2006: Retrieval of cloud phase over the Arctic using MODIS 6.7-12 micron data . $14^{\text {th }}$ Conference on Satellite Meteorology and Oceanography, Atlanta.

Cornman, L., M. Poellot, D. Mulally, and P. Schaffner, 2006: Tropospheric Airborne Meteorological Data Reporting (TAMDAR) Sensor Eddy Dissipation Rate Performance in UND Citation II Flight Tests. 12th Conference on Aviation Range and Aerospace Meteorology, Atlanta, 2006.

Zhang, G., G. McFarquhar, M. Poellot, J. Verlinde, A. Heymsfield, G. and G. Kok, 2005: Derivation of Cloud Heating Rate Profiles using observations of MixedPhase Arctic Clouds: Impacts of Solar Zenith Angle. AGU Fall Meeting, San Francisco.

McFarquhar, G., G. Zhang, M. Poellot, J. Verlinde, G. Kok, and A. Heymsfield, 2005: Recent observations on the vertical profiles of mixed-phase clouds during the Mixed Phase Cloud Experiment (MPACE) and the Alliance Icing Research Study (AIRS)-II. AGU Fall Meeting, San Francisco.

Spangenberg, D., P. Minnis, M. Shupe, M. Poellot, and Z. Wang, 2005: Detection of Mixed-Phase Clouds over the Arctic Using MODIS 6.7-12 micron Data. AGU Fall Meeting, San Francisco.

Mace, Benson, Sonntag, Kato, Min, Minnis, Twohy, Poellot, Dong, Zhang, Long, 2005: Cloud Radiative Forcing at the ARM Climate Research Facility: Part 1. Technique, Validation, and Comparison to Satellite-Derived Diagnostic Quantities. 2005 ARM Science Team Meeting, March 14-18, Daytona Beach.

McFarquhar, Zhang, Verlinde, Poellot, Heymsfield, Kok, 2005: Assessing Current Parameterization of Mixed-Phase Clouds using In Situ Profiles Measured During the Mixed Phase Cloud Experiment. 2005 ARM Science Team Meeting, March 14-18, Daytona Beach. 
Spangenberg, Minnis, Shupe, Uttal, and Poellot, 2005: Retrieval of Cloud Phase Using the Moderate Resolution Imaging Spectroradiometer during the Mixed-Phase Arctic Cloud Experiment. 2005 ARM Science Team Meeting, March 14-18, Daytona Beach.

Verlinde, J., and J. Y. Harrington, G. M. McFarquhar, J. H. Mather, D. Turner, B. Zak, M. R. Poellot, T. Tooman, A. J. Prenni, G. Kok, E. Eloranta, A. Fridlind, C. Bahrmann, K. Sassen, P. J. DeMott, and A. J. Heymsfield, 2005: Overview of the Mixed-Phase Arctic Cloud Experiment (M-PACE). $\underline{\text { th Conference on Polar }}$ Meteorology and Oceanography

Thesis Produced

David L. Brown, "Variability in Microphysical Properties of Mixed-Phase Arctic Clouds." Master of Science, University of North Dakota, December 2007.

\section{References}

Gardiner, B.A. and J. Hallett, 1985: Degradation of in-cloud forward scattering spectrometer probe measurements in the presence of ice particles, J. Atmos. Ocean. Tech., 2, 171-180.

McFarquhar, G.M. and S.G. Cober, 2004: Single-scattering properties of mixed-phase Arctic clouds at solar wavelengths: Impacts on radiative transfer, J. Climate 17, 3799-3813.

McFarquhar, G., G. Zhang, J. Verlinde, M. Poellot, A. Heymsfield and G. Kok, 2005: Assessing Current Parameterization of Mixed-Phase Clouds using In Situ Profiles Measured During the Mixed Phase Cloud Experiment. Fifteenth ARM Science Team Meeting Proceedings, Daytona Beach, Florida, March 14-18, 2005

McFarquhar, G. M., G. Zhang, M. R. Poellot, G. L. Kok, R. McCoy, T. Tooman, A. Fridlind, and A. J. Heymsfield (2007): Ice properties of single-layer stratocumulus during the Mixed-Phase Arctic Cloud Experiment: 1. Observations, J. Geophys. Res., 112, D24201, doi:10.1029/2007JD008633.

Prenni, A. and Coauthors, 2007 : Can Ice-Nucleating Aerosols Affect Arctic Seasonal Climate? Bull. Amer. Meteor. Soc., 88, 541-550. 